\title{
Analyzing the Implications of COVID-19 Pandemic: Saudi Arabian Perspective
}

\author{
Shakeel Ahmed ${ }^{*}$ and Abdulaziz Alhumam \\ Department of Computer Science, College of Computer Sciences and Information Technology, King Faisal University, Al-Ahsa, \\ 31982, Kingdom of Saudi Arabia \\ *Corresponding Author: Shakeel Ahmed. Email: shakeel@kfu.edu.sa \\ Received: 07 December 2020; Accepted: 11 January 2021
}

\begin{abstract}
Most of the patients diagnosed with COVID-19 pandemic usually suffer from mild-to-serious respiratory illness and become stable without any specific care. In fact, in some countries like India the mortality rate is as low. Those who are amongst the most vulnerable groups are the elderly and the ones with chronic ailments like diabetes, heart ailments, and respiratory ailments. However, apart from the impact on the physical health of the patients, this disease has had a more debilitating affect on the mental as well as emotional well-being of the people. Due to continuous watching and protection programs to fight the pandemic, people have been forced into isolation for months and follow social distancing norms without any group interactions. With minimal human-to-human contact and almost no group activities, people are battling with issues of angst, fear and uncertainty. The pandemic has shoved the entire planet into an unstable state. Moreover, the living conditions of everyone have become similar. This research work estimates the impact of COVID-19 pandemic on different aspects of Saudi Arabia's research society. The impact has been evaluated in two dimensions: the early approach, and the late approach of COVID-19 pandemic and the consequent effects in different areas of the research society of Saudi Arabia. In this analysis, we have applied the integrated fuzzy based ANP-TOPSIS approach to evaluate the COVID-19 impact on different aspects of human life. Hence, our study is an attempt to engage the attention of both the government and the policymakers to strategise for an expeditious planning and implementation of measures that will ease the financial duress of the individuals and people of Saudi Arabia.
\end{abstract}

Keywords: Coronavirus; social impact; safety; COVID-19 pandemic monitoring; fuzzy ANP-TOPSIS

\section{Introduction}

Ever since the outbreak of COVID-19 pandemic, people all over the world have been in living in a state of constant anxiety. This global disease has, more or less, influenced the life of every individual, causing loneliness, confusion, frustration, and helplessness. This angst combined with the financial downturn is also the reason for acute depressive symptoms being witnessed by many of us now. The COVID-19 outbreak is a dangerous threat to the research society of Saudi Arabia, both because of the risk of

This work is licensed under a Creative Commons Attribution 4.0 International License, which permits unrestricted use, distribution, and reproduction in any medium, provided the original work is properly cited. 
economic discomfort to humans and because of its unseen mental burden. The epidemic is thought to be the most serious world health tragedy, and also the greatest threat faced by the humanity after the Second World War [1]. On January 31, 2020, the WHO called the outbreak of COVID-19 a Public Health Emergency of International Concern (PHEIC), implying that the pandemic could cause serious damage to many countries, and thus required an urgent, collaborative global response [2]. In addition to the declaration, on 11 March 2020, WHO reported the spread of the COVID-19 epidemic as an "epidemic public health menace". Cases of COVID-19 have evolved alarmingly in many countries around the world since then [3].

The symptoms of this viral infection usually involve fever and coughing, sore throat as well as respiratory problems. To contain the spread of virus, human contact with the infected is considered to be the essential precaution. Hence, social distancing, lockdowns became a mandatory norm for the people. All social interactions, community congregations, business, educational and recreational activities came to a standstill across the world as an attempt to break the chain of the infection's transmission. Human being is a social animal and thrives in an environment of social bonhomie that involves interactions and meets. However the imposition of preventive steps to contain the spread of coronavirus, affected these social relationships with the public distancing measures and separation. The lack of face-to-face contacts and overdependence on digital modes for communication due to shutdowns has led to exhausting conditions of hopelessness, anxiety, depression, psychiatric diseases, health impacts, and several other issues that affect the person's life and the society in general [4]. The outbreak of Novel Coronavirus pandemic is more than just a medical issue: at its heart, it affected the country's economy and different research societies of Saudi Arabia and the rest of the world. While the effects of this epidemic will differ greatly from country to country, it is most likely that poverty and instabilities will increase on a global scale. Several protections, data privacy, and security issues have also arisen from the spread of novel Coronavirus across the world [3-5]. According to the European Centre for Disease Prevention and Control (ECDC), a total of 16.25 million cases have been confirmed worldwide and 649,208 deaths till 27 July 2020, at 10:38 (London Time) [5]. The following Figs. 1 and 2 represent the COVID-19 pandemic confirmed cases and deaths across the world.

Impacts specifically related to the outbreak of COVID-19 and its social effects appear to draw substantial interest from practitioners. Throughout our life-span, we can be afflicted with ailments which are treatable. However, in case of a pandemic outbreak, the disease is not confined to few individuals alone. It begins to affect the people first and then the whole society. Major problems that are encountered in battling against outbreak is generating awareness about the preventive steps to be taken in the absence of socio-cultural knowledge of outbreak, and instabilities found in accessing healthcare facilities. These lacunas become the basis for a large problem from a social point of view. Pandemics are known for causing immense fear among people and lack of accurate information further heightens their anxiety. Epidemics interrupt the process of life, and everybody has a clear history of disease epidemic. So health information starts to rise that is to be carried from present to the next generation. Besides this, the evolving pandemics also affect different sections of the population in a different way. While some influences can alter based on the type of the illness, based on the local functionalities, they can also be transformed from one research society to next.

So, this study tries to apply an integrated Multi-Criteria-Decision-Making (MCDM) method of integrating fuzzy Analytic Network Process (ANP) with fuzzy Technique for Order of Preference by Similarity to Ideal Solution (TOPSIS) to evaluate the impact of coronavirus on research society of Saudi Arabia. In addition, we selected different community characteristics that were severely affected by novel Coronavirus pandemic. These characteristics are based on certain parameters mentioned in [2-5]. MCDM is the most important component of our analysis; the technique enabled the practitioners to make their key judgments in a precise way. Such MCDM theories are based on decision-making issues. With regard to such variables, individuals selected the appropriate alternatives/ or choices in the MCDM framework. These MCDM frameworks are recently being applied to resolve the various decision making problems pertaining to novel Coronavirus pandemic [6-10]. 
IASC, 2021, vol.27, no.3

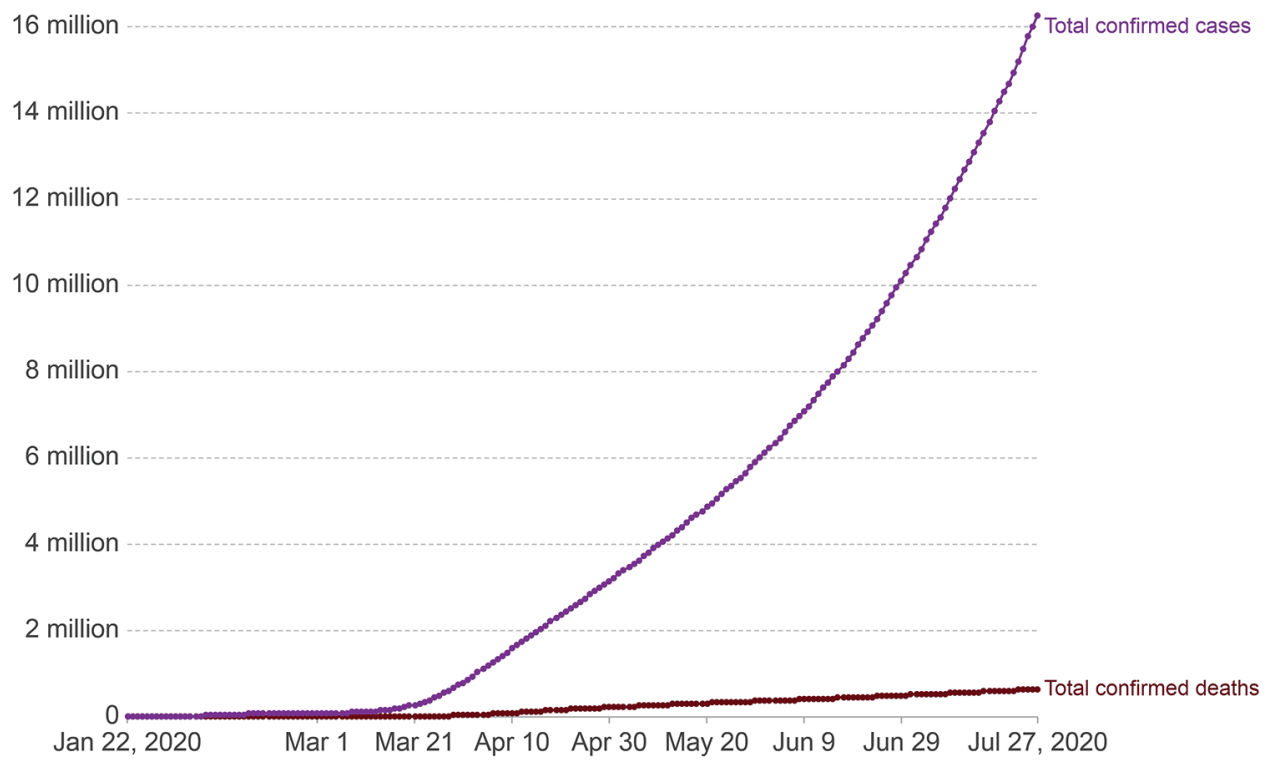

Figure 1: Worldwide total confirmed COVID-19 deaths and cases

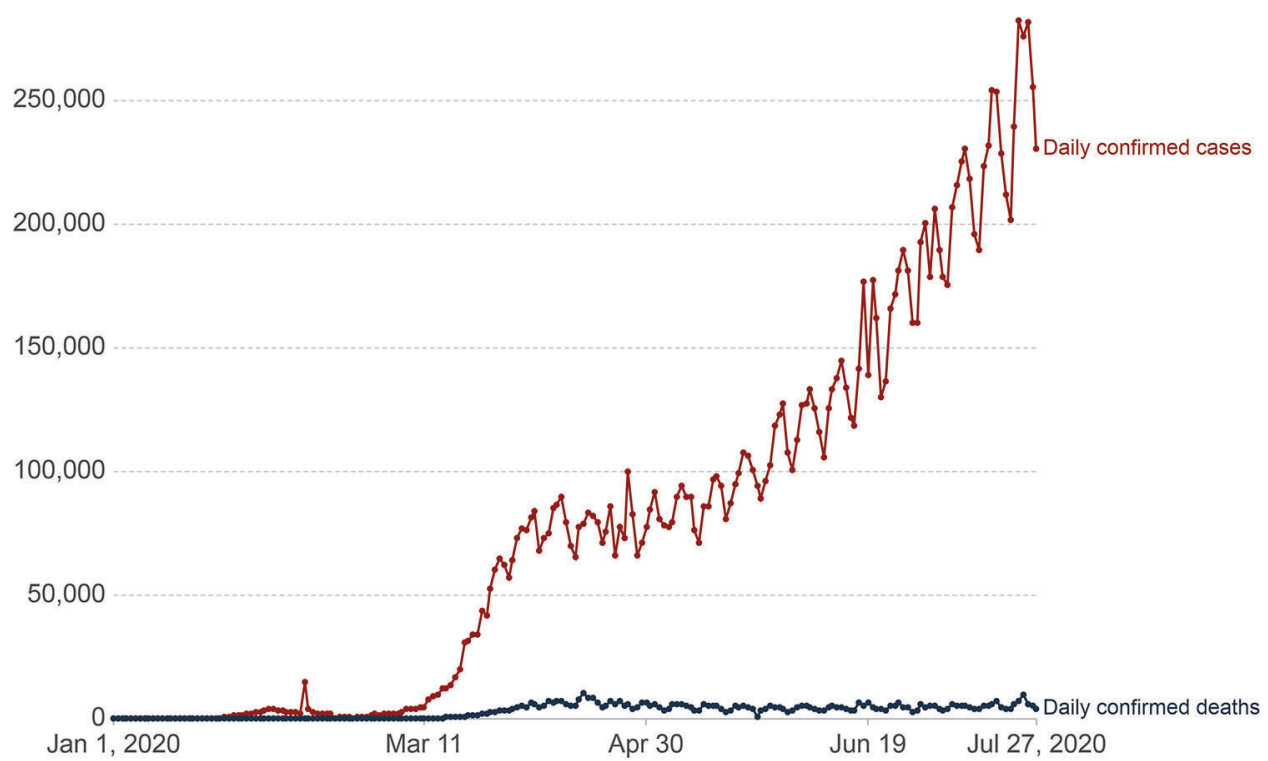

Figure 2: Number of daily confirmed cases of COVID-19 pandemic and deaths worldwide

\section{Materials and Methods}

\subsection{Criteria and Alternatives Selection}

For designing the empirical framework of our study, we reviewed the existing literature and collated the opinions of experts through questionnaire-based surveys [11-15]. For selecting the social factors that were affected by the outbreak of the novel coronavirus epidemic, we reviewed nearly 30 different publications. Since our target was to conduct social impact analysis, the opinions of academic experts were the most integral aspect of our research. We collated the responses of 43 experts from a group of 60 experts and researchers. Thereafter, we listed the social factors that were highly affected by the epidemic. 
The effect of COVID-19 pandemic on society is expected to be based on 7 parameters $(F i)$ and 7 alternatives sites $(A i)$ are responsible. The 7 key specifications are: Monitoring (F1), Screening (F2), Scoping (F3), Risk (F4), Guidance (F5), Assessment (F6) and Reporting (F7). Seven alternatives are: Education (A1), Financial (A2),Emotional (A3), Religion (A4), Work (A5), Relationships (A6), and Psychological (A7). In the second stage of the current process, because of COVID-19 pandemic spread, the alternatives are chosen as impacted factors in Saudi Arabia's research society. These factors are identified by reviewing the existing relevant literature, and then selected by a panel of specialists. Tab. 1 outlines all the parameters defined for determining the affect of the epidemic on various social factors. The hierarchical depiction of our judgment issue is shown in Fig. 3.

Table 1: COVID-19 pandemic social impact evaluation criteria

\begin{tabular}{|c|c|c|}
\hline Criteria & Description & Reference \\
\hline $\begin{array}{l}\text { Monitoring } \\
\text { (F1) }\end{array}$ & $\begin{array}{l}\text { Monitor patients of COVID- } 19 \text { pandemic so that they are able to feel safe at } \\
\text { hospital/home and could be recommended to get proper care when needed. }\end{array}$ & [10] \\
\hline $\begin{array}{l}\text { Screening } \\
\text { (F2) }\end{array}$ & $\begin{array}{l}\text { A screening test is completed as an anticipatory measure to identify potential } \\
\text { health issues or disease in individual who doesn't yet have symptoms of } \\
\text { COVID-19 pandemic. The determination of screening is early approach. }\end{array}$ & {$[11]$} \\
\hline $\begin{array}{l}\text { Scoping } \\
\text { (F3) }\end{array}$ & $\begin{array}{l}\text { An appropriately defined and accomplished scope leads to conveying a quality } \\
\text { service, at a specific cost and within the stated schedules to the people during } \\
\text { pandemic. }\end{array}$ & {$[12]$} \\
\hline Risk (F4) & $\begin{array}{l}\text { Risk refers to the possibility that anything negative will occur. Risk entails } \\
\text { speculation about repercussions/considerations of an action on something that } \\
\text { is of interest to individuals like health, well-being, income, assets or the } \\
\text { ecosystem. }\end{array}$ & {$[13]$} \\
\hline $\begin{array}{l}\text { Guidance } \\
\text { (F5) }\end{array}$ & $\begin{array}{l}\text { Guidance is significant societal step against pandemic situation as it helps in } \\
\text { early identification of the possible risks. Effective guidelines also serve as } \\
\text { timely preventive mechanisms which people can adopt to keep themselves } \\
\text { healthy. }\end{array}$ & [14] \\
\hline $\begin{array}{l}\text { Assessment } \\
\text { (F6) }\end{array}$ & $\begin{array}{l}\text { Pandemic assessment is crucial for the research society of Saudi Arabia as } \\
\text { during this process the decision makers are estimating the possibilities of the } \\
\text { spread of coronavirus and the number of individuals that are at risk due to it in } \\
\text { the research society of Saudi Arabia. It may be summative, interim and } \\
\text { formative. }\end{array}$ & {$[15]$} \\
\hline $\begin{array}{l}\text { Reporting } \\
\text { (F7) }\end{array}$ & $\begin{array}{l}\text { The effective pandemic reporting, analytics and information delivery approach } \\
\text { can have a significant impact on the research society of Saudi Arabia; it might } \\
\text { alter the way people execute their tasks and how the choices are made. }\end{array}$ & {$[16]$} \\
\hline
\end{tabular}

\subsection{Fuzzy ANP-TOPSIS Method}

\subsubsection{Fuzzy ANP}

T.L. Saaty introduced ANP [12]. The Analytical Hierarchy Process (AHP) is a unidirectional non-linear hierarchical assembly system, and ANP allows for efficient connectivity between decision levels and attributes [12-13]. In addition, fora complicated operation, a continuous top-to-bottom design is not sufficient. Since affiliation and dependency of higher level elements are involved, most of the existing problems could not be hierarchically structured [12,14]. Through the structuring of a functional 
dependence problem, responses among clusters are possible. Saaty [12] suggested the use of AHP to correct parameters as a problem of freedom, including the use of ANP to address the issue of alternative on parameters. In ANP, the structural weight can be achieved by constructing supermatrix to control interdependencies between parameters; mainly where the ANP takes dominance over AHP and produces a difference [15].

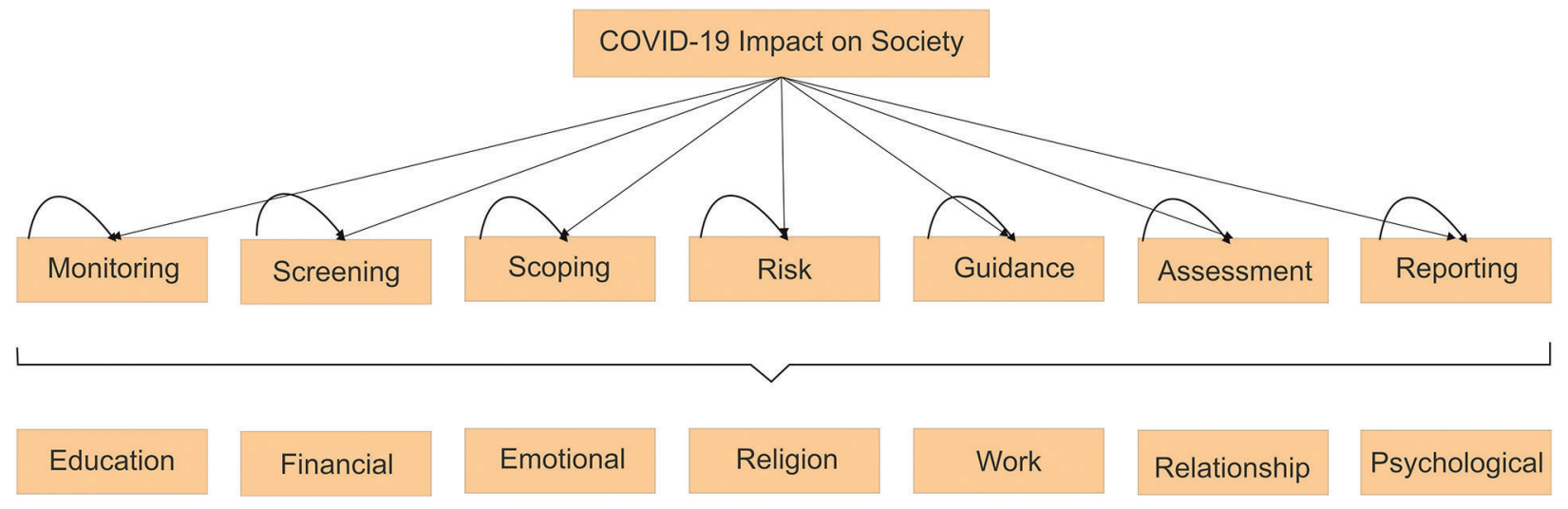

Figure 3: ANP structure of the COVID-19 pandemic social impact evaluation

\subsubsection{Fuzzy TOPSIS}

TOPSIS is most common MCDM procedure and is used in many application areas. Hwang and Yoon [16] were the first to observe that the MCDM challenges can be resolved by using the basic concept of choosing an approach that ranges from the shortest distance from the positive (best) ideal solution, and the longest from the negative-ideal (poorest) resolution. Chen [17] successfully applied the TOPSIS scheme into a floating world by using TFNs to replace the quantitative linguistic rating and weighting rates. Thereafter, a variety of approaches are proposed to modify the TOPSIS method. In this row, the decision making process is carried out by applying Chen's [16] fuzzy TOPSIS method. In the fuzzy world, this procedure is suitable to tackle the community challenge of decision making. Linguistic procedures are used in this scheme for determining the significance weights of defined criteria and allocating the ratings of qualitative criteria [18-20].

Fig. 4 depicts the procedure of using F-ANP and F-TOPSIS to measure the impact on research society of Saudi Arabia of COVID-19 pandemic.

The entire methodology can be detailed in the following steps:

Step-I: Triangular Fuzzy Number (TFN): The conversion starts from linguistic terms to numeric values and then into TFN values. TFN is carried as function of membership and is between 0 and 1 [18-19]. Structural definition of a TFN is as: $(r, s, t)$, where $(r \leq s \leq t)$ and in a TFN $r, s, t$ represents the smallest, the middle value, and the largest value, respectively. Further, if Eqs. (1) and (2) provides a fuzzy number $\mathrm{N}$ membership function on F, So it is called the TFN and depicted in Fig. 5 [19-20].

$\mu_{\mathrm{A}}(\mathrm{x})=\mathrm{F} \rightarrow[0,1]$

$\mu_{A}(x)= \begin{cases}\frac{x-r}{s-r}, & r \leq x \leq s \\ \frac{t-x}{t-s}, & s \leq x \leq t \\ 0 \quad, & x>t \quad \text { Otherwise }\end{cases}$ 


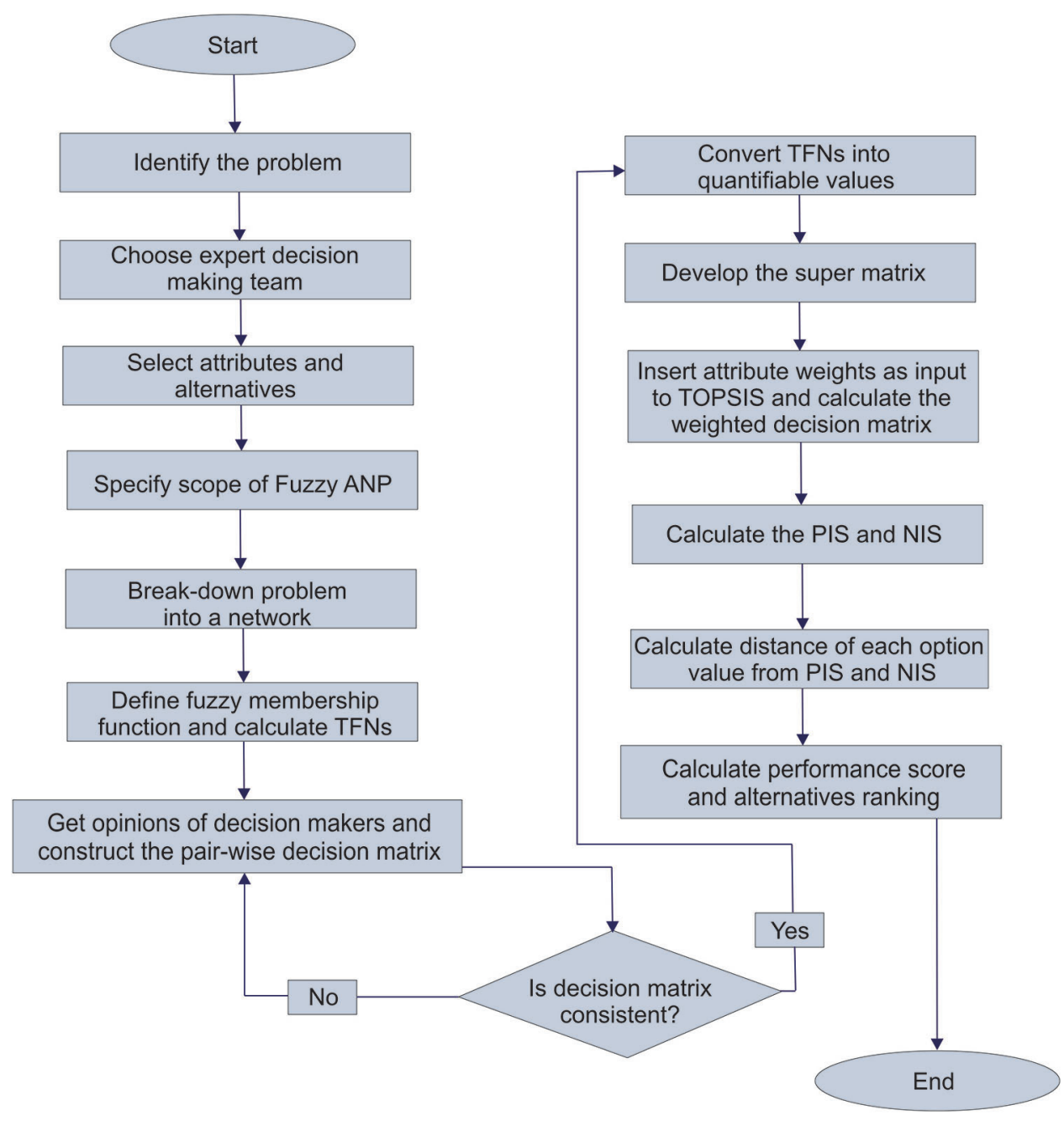

Figure 4: Fuzzy-ANP-TOPSIS procedure

Different academic researchers and domain experts have been approached through virtual mode and their opinions are considered to identify characteristics. The experts assigned the scores to the characteristics that affect everyone in noticeable way. Furthermore, the practitioners referred to the Saaty's scale (Tab. 2) for assigning linguistic terms and then their corresponding numeric values to each characteristic. Thereafter, the numeric values are converted into fuzzy numbers.

Conversion from numeric values into TFN is performed with help of Eqs. (3)-(6) [20-21] and represented as $\left(r_{i j}, s_{i j}, t_{i j}\right)$ where, $r_{i j}$ denotes lower-value, $s_{i j}$ denotes middle-value and $t_{i j}$ denotes uppervalue. Further, TFN [nij] is defined as following:

$\eta_{i j}=\left(r_{i j}, s_{i j}, t_{i j}\right)$

where, $\quad r_{i j} \leq s_{i j} \leq t_{i j}$

$r_{i j}=\min \left(J_{i j d}\right)$ 
IASC, 2021, vol.27, no.3

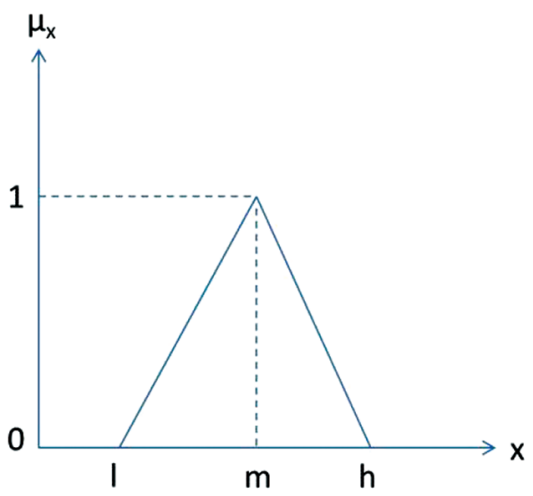

Figure 5: Triangular fuzzy number

Table 2: TFNs respect to Linguistic-terms

\begin{tabular}{llc}
\hline Saaty Scale Definition & \multicolumn{2}{c}{ Fuzzy Triangle Scale } \\
\hline 1 & Equally important & $(1,1,1)$ \\
3 & Weakly important & $(2,3,4)$ \\
5 & Fairly important & $(4,5,6)$ \\
7 & Strongly important & $(6,7,8)$ \\
9 & Absolutely important & $(9,9,9)$ \\
2 & Intermittent values between two adjacent scales & $(1,2,3)$ \\
4 & & $(3,4,5)$ \\
6 & & $(5,6,7)$ \\
8 & & $(7,8,9)$ \\
\hline
\end{tabular}

$s_{i j}=\left(J_{i j 1}, J_{i j 2}, J_{i j 3}\right)^{\frac{1}{x}}$

and $\quad t_{i j}=\max \left(J_{i j d}\right)$

where, $J_{i j k}$ represents relative importance of the values between two characteristics. Experts judged a pair of characteristics and represented it by $i$ and $j$. Geometric mean of the experts' choices became the base for estimating the TFN $\left(\eta_{\mathrm{ij}}\right)$. Further, to TFN values Eqs. (7)-(9) has been applied. Let two TFNs are N1 and $\mathrm{N} 2$ : $\mathrm{N} 1=\left(\mathrm{l}_{1}, \mathrm{~m}_{1}, \mathrm{n}_{1}\right)$ and $\mathrm{N} 2=\left(\mathrm{l}_{2}, \mathrm{~m}_{2}, \mathrm{n}_{2}\right)$. To perform operations on two TFNs, the following rules of operations are adopted:

$\left(l_{1}, m_{1}, n_{1}\right)+\left(l_{2}, m_{2}, n_{2}\right)=\left(l_{1}+l_{2}, m_{1}+m_{2}, n_{1}+n_{2}\right)$

$\left(l_{1}, m_{1}, n_{1}\right) \times\left(l_{2}, m_{2}, n_{2}\right)=\left(l_{1} * l_{2}, m_{1} * m_{2}, n_{1} * n_{2}\right)$

$\left(l_{1}, m_{1}, n_{1}\right)^{-1}=\left(\frac{1}{n_{1}}, \frac{1}{m_{1}}, \frac{1}{l_{1}}\right)$

Step-II: With the help of the decision-makers' opinions, pair-wise comparison matrix is assembled. Consistency Index (CI) is calculated by applying the Eq. (10): 
$C I=\frac{\gamma_{\max }-n}{n-1}$

where, $\mathrm{n}$ denotes number of compared elements.

In addition, Consistency Ratio (CR) is calculated by using Eq. (11):

$C R=C I / R I$

The matrix generated is called consistent if CR $<0.1$ and Random Index is specified by RI and is taken from [21-22].

Step-III: Defuzzification method is taken from [22-24] where TFN values are aggregated in common values. Further, defuzzification is determined through Eqs. (12)-(14).

$\mu_{\alpha, \beta}\left(\eta_{i j}\right)=\left[\beta . \eta \alpha\left(r_{i j}\right)+(1-\beta) \cdot \eta \alpha\left(t_{i j}\right)\right]$

where, $0 \leq \alpha \leq 1$ and $0 \leq \beta \leq 1$

Such that,

$\eta \alpha\left(r_{i j}\right)=\left(s_{i j}-r_{i j}\right) \cdot \alpha+r_{i j}$

$\eta \alpha\left(t_{i j}\right)=t_{i j}-\left(t_{i j}-s_{i j}\right) \cdot \alpha$

The $\alpha$ and $\beta$ values lie between [0-1].

Step-IV: In this step, the process of comparisons between pairs with objective, attributes, sub-attributes, and alternatives in the form of priority vector are done.

Step-V: TOPSIS is used to performance evaluation of each alternative with respect to each normalized factor and is calculated by Eq. (15):

$X_{i j}=\frac{x_{i j}}{\sqrt{\sum_{i=1}^{m} x_{i j}^{2}}}$

where, $\mathrm{i}=1$ to $\mathrm{m}$; and $\mathrm{j}=1 \ldots \mathrm{n}$.

Now, with the help of Eq. (16), calculations are performed to construct normalized weighted decision matrix.

$D_{i j}=w_{i} X_{i j}$

where, $i=1$ to $m$ and $j=1 \ldots n$.

Step-VI: In this step, Positive Ideal Solution (PIS $\left(\mathrm{V}^{+}\right)$) and Negative Ideal Solution (NIS $\left(\mathrm{V}^{-}\right)$) are obtained with the help of Eq. (17).

$$
\begin{aligned}
V^{+} & =p_{1}^{+}, p_{2}^{+}, p_{3}^{+} \ldots . p_{n}^{+} \\
V^{-} & =p_{1}^{-}, p_{2}^{-}, p_{3}^{-} \ldots . p_{n}^{-}
\end{aligned}
$$

where, $p_{j}^{+}$is max $p_{\mathrm{ij}}$, if $\mathrm{j}$ is an advantage factor, and max $\mathrm{p}_{\mathrm{ij}}$, if $\mathrm{j}$ is a cost factor; $p_{j^{-}}$is min $\mathrm{p}_{\mathrm{ij}}$ if $\mathrm{j}$ is an advantage factor and Min $\mathrm{p}_{\mathrm{ij}}$, if $\mathrm{j}$ is a cost factor.

Step-VII: In this step, the distance of each alternative value from PIS and NIS is identified with the help of Eqs. (18) and (19). 
$s_{i}^{+}=\sqrt{\sum_{j=1}^{m}\left(p_{i}^{+}-p_{i j}\right)^{2}} ; i=1$ to $m$

$s_{i}^{-}=\sqrt{\sum_{j=1}^{m}\left(p_{i j}-p_{i}^{-}\right)^{2}} ; \quad$ where, $i=1$ to $m$

where, the distance to PIS for the alternative is defined by $s_{j}^{+}$and the distance to NIS for the alternative is defined by $s_{i}^{-}$.

For each alternative $\left(\mathrm{P}_{\mathrm{i}}\right)$, the preference value is calculated with the Eq. (20).

$P=\frac{s_{i}^{-}}{s_{i}^{-}-s_{i}^{+}}$

where, $\mathrm{i}=1,2,3 \ldots \mathrm{m}$

The above mentioned procedure is applied to estimate the impact of the COVID-19 pandemic on research society of Saudi Arabia by using integrated fuzzy ANP-TOPSIS approach. The next section performs a case study and gives the numerical assessment.

\section{Data Analysis and Findings}

The impact of COVID-19 pandemic on different aspects of social factors is measured by using the two MCDM techniques of AHP and TOPSIS under fuzzy environment. With the help of Tab. 2 and Eqs. (1)-(15), we converted the linguistic-terms into Saaty Scale and then in TFN values. For transforming the precise numerical values in TFN values, Eqs. (3)-(6) and Eq. (16) have been applied. Then, the evaluated the pair-wise comparison matrix. In the ensuing steps, the CI, RI and defuzzification values are determined by using Eqs. (10) and (11) and Eqs. (12)-(14), respectively. Random index of pair-wise comparison is less than 0.1 which verifying the consistency of the matrix. The calculated values and global weights are shown in Tabs. 3-5, respectively. Finally, with the help of Eqs. (17)-(20), closeness coefficients of different alternatives are obtained. The calculated results are shown in Tabs. 6-9 and Fig. 6, respectively.

Table 3: Pair-wise comparison matrix

\begin{tabular}{llllllll}
\hline & F1 & F2 & F3 & F4 & F5 & F6 & F7 \\
\hline F1 & 1.00000, & 0.56110, & 1.74140, & 0.61740, & 0.49475, & 1.04525, & 0.4450, \\
& 1.00000, & 0.66120, & 2.34130, & 0.93574, & 0.65457, & 1.00470, & 0.51450, \\
& 1.00000 & 0.75130 & 2.91440 & 1.06457 & 0.84472 & 1.00747 & 0.66450 \\
F2 & 0.50140, & 1.00000, & 1.18450, & 0.79598, & 1.46145, & 1.33788, & 1.55450, \\
& 0.65450, & 1.00000, & 1.47560, & 0.96856, & 1.86450, & 1.52785, & 2.20450, \\
& 0.94254 & 1.00000 & 1.87527 & 1.14858 & 2.22450 & 1.80787 & 2.85045 \\
F3 & 1.16140, & 0.53045, & 1.00000, & 1.09858, & 1.61547, & 0.34778, & 1.40470, \\
& 1.67120, & 0.68450, & 1.00000, & 1.34859, & 2.34758, & 0.43775, & 1.82478, \\
& 1.96130 & 0.85470 & 1.00000 & 1.87898 & 3.15478 & 0.57857 & 2.45759 \\
F4 & 0.34170, & 0.88457, & 0.53470, & 1.00000, & 1.54578, & 0.95859, & 1.25457, \\
& 0.43150, & 1.04457, & 0.74450, & 1.00000, & 1.93589, & 1.08865, & 1.64457, \\
& 0.58650 & 1.26470 & 0.53456 & 1.00000 & 2.35589 & 1.64589 & 2.03458 \\
\hline
\end{tabular}




\begin{tabular}{|c|c|c|c|c|c|c|c|}
\hline & $\mathrm{F} 1$ & $\mathrm{~F} 2$ & F3 & F4 & F5 & F6 & F7 \\
\hline F5 & $\begin{array}{l}0.32250 \\
0.41250 \\
0.59230\end{array}$ & $\begin{array}{l}0.45456 \\
0.54450 \\
0.69450\end{array}$ & $\begin{array}{l}1.14580, \\
1.56459, \\
1.81589\end{array}$ & $\begin{array}{l}0.42089 \\
0.52079 \\
0.67077\end{array}$ & $\begin{array}{l}1.00000 \\
1.00000 \\
1.00000\end{array}$ & $\begin{array}{l}1.19860 \\
1.54880 \\
2.03589\end{array}$ & $\begin{array}{l}1.14581, \\
1.49447, \\
1.90548\end{array}$ \\
\hline F6 & $\begin{array}{l}0.38220 \\
0.48230 \\
0.63240\end{array}$ & $\begin{array}{l}0.56750 \\
0.66470 \\
0.75470\end{array}$ & $\begin{array}{l}1.74010, \\
2.34020, \\
2.99030\end{array}$ & $\begin{array}{l}0.61078 \\
0.93075 \\
1.06075\end{array}$ & $\begin{array}{l}0.49459 \\
0.65589 \\
0.84568\end{array}$ & $\begin{array}{l}1.00000 \\
1.00000 \\
1.00000\end{array}$ & $\begin{array}{l}0.40457, \\
0.51457 \\
0.66441\end{array}$ \\
\hline F7 & $\begin{array}{l}1.10240 \\
1.56470 \\
1.81457\end{array}$ & $\begin{array}{l}0.35745 \\
0.45457 \\
0.64758\end{array}$ & $\begin{array}{l}0.41040, \\
0.55070, \\
0.71047\end{array}$ & $\begin{array}{l}0.49047 \\
0.61045 \\
0.80045\end{array}$ & $\begin{array}{l}0.53589 \\
0.67589 \\
0.84586\end{array}$ & $\begin{array}{l}1.51568, \\
1.96589, \\
2.51568\end{array}$ & $\begin{array}{l}1.00000 \\
1.00000 \\
1.00000\end{array}$ \\
\hline
\end{tabular}

Table 4: Defuzzification and weights of characteristics

\begin{tabular}{lllllllll}
\hline & F1 & F2 & F3 & F4 & F5 & F6 & F7 & Weightage \\
\hline F1 & 1.00000 & 1.77145 & 0.89145 & 2.56478 & 2.66458 & 2.34474 & 0.93652 & 0.288200 \\
F2 & 0.56245 & 1.00000 & 1.72541 & 1.21145 & 1.85452 & 1.79475 & 2.41145 & 0.189000 \\
F3 & 1.12457 & 0.57100 & 1.00000 & 0.98457 & 2.60454 & 0.69457 & 2.12124 & 0.165000 \\
F4 & 0.39454 & 0.82457 & 1.01475 & 1.00000 & 2.17744 & 0.77745 & 1.89425 & 0.133000 \\
F5 & 0.37457 & 0.54741 & 0.38585 & 0.45589 & 1.00000 & 1.82457 & 1.76745 & 0.257410 \\
F6 & 0.42741 & 0.55457 & 1.44745 & 1.29765 & 0.54457 & 1.00000 & 1.43645 & 0.118900 \\
F7 & 1.07156 & 0.41245 & 0.47357 & 0.52652 & 0.56652 & 0.69458 & 1.00000 & 0.090460 \\
& & & & & & & & CR $=0.07200$ \\
\hline
\end{tabular}

Table 5: Global weights

\begin{tabular}{|c|c|c|}
\hline Attributes & Global Weights & Global Priorities \\
\hline $\mathrm{F} 1$ & 0.1891240 & 2 \\
\hline $\mathrm{F} 2$ & 0.2074570 & 1 \\
\hline F3 & 0.1851450 & 3 \\
\hline $\mathrm{F} 4$ & 0.1654710 & 4 \\
\hline F5 & 0.1124550 & 5 \\
\hline F6 & 0.0724560 & 6 \\
\hline F7 & 0.0678920 & 7 \\
\hline
\end{tabular}

The Closeness Coefficient (Ci) of various alternatives is assessed (Tab. 9 and Fig. 6) as 0.31215, $0.32425,0.21245,0.27859,0.27854,0.28457$ and 0.25658 for A1, A2, A3, A4, A5, A6 and A7, respectively. The results indicate that A2 is strongly influenced by COVID-19 epidemic. 
Table 6: Subjective cognition results of evaluators in linguistic terms

\begin{tabular}{llllllll}
\hline $\begin{array}{l}\text { Attributes/ } \\
\text { Alternatives }\end{array}$ & A1 & A2 & A3 & A5 & A6 & A7 \\
\hline F1 & 6.27000, & 3.91000, & 3.18000, & 1.64000, & 1.18000, & 4.45000, & 1.18000, \\
& 8.27000, & 5.91000, & 5.18000, & 3.36000, & 3.00000, & 6.45000, & 3.00000, \\
& 9.45000 & 7.55000 & 7.00000 & 5.36000 & 5.00000 & 8.00000 & 5.00000 \\
F2 & 3.18000, & 1.64000, & 1.18000, & 4.45000, & 1.18000, & 3.00000, & 0.64000, \\
& 5.18000, & 3.36000, & 3.00000, & 6.45000, & 3.00000, & 4.82000, & 2.27000, \\
& 7.00000 & 5.36000 & 5.00000 & 8.00000 & 5.00000 & 6.55000 & 4.27000 \\
F3 & 4.82000, & 1.00000, & 0.64000, & 3.00000, & 0.64000, & 3.55000, & 0.36000, \\
& 6.82000, & 2.64000, & 2.27000, & 4.82000, & 2.27000, & 5.36000, & 1.73000, \\
& 8.27000 & 4.64000 & 4.27000 & 6.55000 & 4.27000 & 7.00000 & 3.73000 \\
F4 & 4.09000, & 0.73000, & 0.36000, & 3.55000, & 0.36000, & 4.45000, & 1.18000, \\
& 6.09000, & 2.27000, & 1.73000, & 5.36000, & 1.73000, & 6.45000, & 3.00000, \\
& 7.73000 & 4.27000 & 3.73000 & 7.00000 & 3.73000 & 8.00000 & 5.00000 \\
F5 & 3.18000, & 1.64000, & 1.18000, & 4.45000, & 1.18000, & 3.00000, & 0.73000, \\
& 5.18000, & 3.36000, & 3.00000, & 6.45000, & 3.00000, & 4.82000, & 2.45000, \\
& 7.00000 & 5.36000 & 5.00000 & 8.00000 & 5.00000 & 6.55000 & 4.45000 \\
F6 & 3.55000, & 0.82000, & 0.73000, & 3.00000, & 0.73000, & 3.00000, & 0.64000, \\
& 5.55000, & 2.45000, & 2.45000, & 4.82000, & 2.45000, & 4.82000, & 2.27000, \\
& 7.27000 & 4.45000 & 4.45000 & 6.55000 & 4.45000 & 6.55000 & 4.27000 \\
F7 & 4.82000, & 1.00000, & 0.64000, & 3.00000, & 0.64000, & 3.55000, & 0.36000, \\
& 6.82000, & 2.64000, & 2.27000, & 4.82000, & 2.27000, & 5.36000, & 1.73000, \\
& 8.27000 & 4.64000 & 4.27000 & 6.55000 & 4.27000 & 7.00000 & 3.73000 \\
\hline
\end{tabular}

Table 7: The normalized fuzzy-decision matrix

\begin{tabular}{llllllll}
\hline $\begin{array}{l}\text { Attributes/ } \\
\text { Alternatives }\end{array}$ & A1 & A2 & A3 & A4 & A5 & A6 & A7 \\
\hline F1 & 0.17000, & 0.17000, & 0.11000, & 0.37000, & 0.17000, & 0.37000, & 0.14000, \\
& 0.46000, & 0.46000, & 0.40000, & 0.60000, & 0.46000, & 0.60000, & 0.42000, \\
& 0.80000 & 0.80000 & 0.76000 & 0.81000 & 0.80000 & 0.81000 & 0.77000 \\
F2 & 0.12000, & 0.12000, & 0.06000, & 0.44000, & 0.12000, & 0.37000, & 0.17000, \\
& 0.39000, & 0.39000, & 0.31000, & 0.67000, & 0.39000, & 0.60000, & 0.46000, \\
& 0.74000 & 0.74000 & 0.67000 & 0.87000 & 0.74000 & 0.81000 & 0.80000 \\
F3 & 0.06000, & 0.44000, & 0.12000, & 0.12000, & 0.06000, & 0.44000, & 0.12000, \\
& 0.31000, & 0.67000, & 0.39000, & 0.39000, & 0.31000, & 0.67000, & 0.39000, \\
& 0.67000 & 0.87000 & 0.74000 & 0.74000 & 0.67000 & 0.87000 & 0.74000 \\
F4 & 0.21000, & 0.55000, & 0.28000, & 0.28000, & 0.21000, & 0.55000, & 0.28000, \\
& 0.54000, & 0.80000, & 0.58000, & 0.58000, & 0.54000, & 0.80000, & 0.58000, \\
& 0.90000 & 1.00000 & 0.93000 & 0.93000 & 0.90000 & 1.00000 & 0.93000 \\
\hline
\end{tabular}




\begin{tabular}{llllllll}
\hline \multicolumn{6}{l}{ Table 7 (continued). } & \multicolumn{7}{l}{ A3 } & A5 & A6 & A7 \\
\hline $\begin{array}{l}\text { Attributes/ } \\
\text { Alternatives }\end{array}$ & A1 & A2 & A3 & A4 & & & \\
\hline F5 & 0.13000, & 0.37000, & 0.14000, & 0.14000, & 0.13000, & 0.37000, & 0.14000, \\
& 0.44000, & 0.60000, & 0.42000, & 0.42000, & 0.44000, & 0.60000, & 0.42000, \\
& 0.80000 & 0.81000 & 0.77000 & 0.77000 & 0.80000 & 0.81000 & 0.77000 \\
F6 & 0.11000, & 0.37000, & 0.17000, & 0.17000, & 0.11000, & 0.37000, & 0.17000, \\
& 0.40000, & 0.60000, & 0.46000, & 0.46000, & 0.40000, & 0.60000, & 0.46000, \\
& 0.76000 & 0.81000 & 0.80000 & 0.80000 & 0.76000 & 0.81000 & 0.80000 \\
F7 & 0.06000, & 0.44000, & 0.12000, & 0.12000, & 0.06000, & 0.44000, & 0.12000, \\
& 0.31000, & 0.67000, & 0.39000, & 0.39000, & 0.31000, & 0.67000, & 0.39000, \\
& 0.67000 & 0.87000 & 0.74000 & 0.74000 & 0.67000 & 0.87000 & 0.74000 \\
\hline
\end{tabular}

Table 8: The weighted normalized fuzzy-decision matrix

\begin{tabular}{llllllll}
\hline $\begin{array}{l}\text { Attributes/ } \\
\text { Alternatives }\end{array}$ & A1 & A2 & A3 & A4 & A5 & A6 & A7 \\
\hline F1 & 0.02800, & 0.07400, & 0.06800, & 0.02800, & 0.07400, & 0.06800, & 0.04800, \\
& 0.07200, & 0.10700, & 0.10400, & 0.07200, & 0.10700, & 0.10400, & 0.08700, \\
F2 & 0.12000 & 0.13400 & 0.13400 & 0.12000 & 0.13400 & 0.13400 & 0.12900 \\
& 0.01300, & 0.03800, & 0.03800, & 0.01300, & 0.03800, & 0.03800, & 0.06800, \\
& 0.04500, & 0.06200, & 0.06500, & 0.04500, & 0.06200, & 0.06500, & 0.10400, \\
F3 & 0.08200 & 0.08300 & 0.09000 & 0.08200 & 0.08300 & 0.09000 & 0.13400 \\
& 0.01300, & 0.04400, & 0.04400, & 0.01300, & 0.04400, & 0.04400, & 0.03800, \\
& 0.04700, & 0.07100, & 0.07500, & 0.04700, & 0.07100, & 0.07500, & 0.06500, \\
F4 & 0.09000 & 0.09600 & 0.10600 & 0.09000 & 0.09600 & 0.10600 & 0.09000 \\
& 0.02400, & 0.04400, & 0.01100, & 0.00500, & 0.04000, & 0.02400, & 0.06800, \\
& 0.04600, & 0.06600, & 0.03500, & 0.02800, & 0.06100, & 0.04600, & 0.10400, \\
F5 & 0.07000 & 0.08400 & 0.06700 & 0.06100 & 0.07900 & 0.07000 & 0.13400 \\
& 0.01400, & 0.01300, & 0.03800, & 0.03800, & 0.01300, & 0.03800, & 0.03800, \\
& 0.04300, & 0.04500, & 0.06200, & 0.06500, & 0.04500, & 0.06200, & 0.06500, \\
F6 & 0.07900 & 0.08200 & 0.08300 & 0.09000 & 0.08200 & 0.08300 & 0.09000 \\
& 0.02000, & 0.01300, & 0.04400, & 0.04400, & 0.01300, & 0.04400, & 0.04400, \\
& 0.05500, & 0.04700, & 0.07100, & 0.07500, & 0.04700, & 0.07100, & 0.07500, \\
F7 & 0.09500 & 0.09000 & 0.09600 & 0.10600 & 0.09000 & 0.09600 & 0.10600 \\
& 0.05100, & 0.02400, & 0.04400, & 0.01100, & 0.00500, & 0.04000, & 0.02400, \\
& 0.07000, & 0.04600, & 0.06600, & 0.03500, & 0.02800, & 0.06100, & 0.04600, \\
& 0.08300 & 0.07000 & 0.08400 & 0.06700 & 0.06100 & 0.07900 & 0.07000 \\
\hline
\end{tabular}


Table 9: Closeness coefficients to the aspired level among the different alternatives

\begin{tabular}{llll}
\hline Alternatives & $\mathrm{d}+\mathrm{i}$ & $\mathrm{d}-\mathrm{i}$ & $\mathrm{Ci}$ \\
\hline Alternative (A1) & 0.16142 & 0.07552 & 0.31215 \\
Alternative (A2) & 0.24124 & 0.11895 & 0.32425 \\
Alternative (A3) & 0.23458 & 0.07545 & 0.21245 \\
Alternative (A4) & 0.45457 & 0.16658 & 0.27859 \\
Alternative (A5) & 0.47758 & 0.17569 & 0.27854 \\
Alternative (A6) & 0.17596 & 0.06785 & 0.28457 \\
Alternative (A7) & 0.34578 & 0.09578 & 0.25658 \\
\hline
\end{tabular}

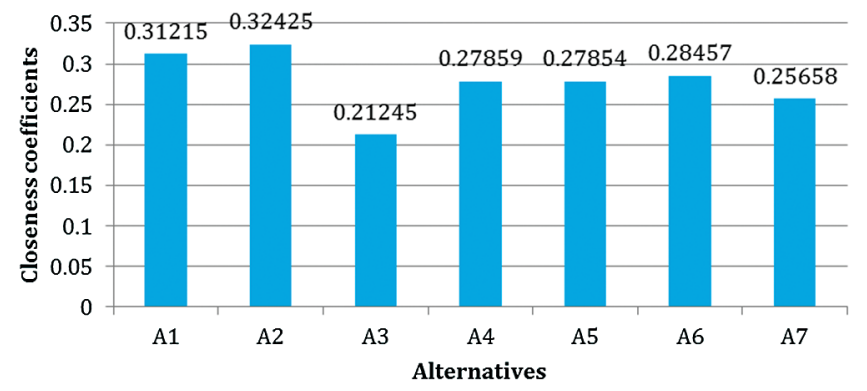

Figure 6: Graphical representation of the closeness coefficients for alternatives

\section{Validations of Results}

\subsection{Sensitivity Analysis}

An interpretation of the findings obtained from the various viewpoints is crucial for every scientific research study. One of the most powerful and reliable procedures for authenticating the relevance of the result is the sensitivity analysis protocol [25-26]. Furthermore, the sensitivity study provides data analysis researchers a method to analyze their results. In this study, the planned analysis used 7 experimental studies to test sensitivity since there are 7 variables in the first hierarchy level. The sensitivity weights of all factors are distinctive at the time of measurement, and at the same time, the other weights and level of satisfaction are stable. The evaluated result of the important study of sensitivity is shown in Tab. 10 and Fig. 7.

Table 10: Sensitivity analysis

\begin{tabular}{lllllllll}
\hline Alternatives & Original Weights & F1 & F2 & F3 & F4 & F5 & F6 & F7 \\
\hline Alternative (A1) & 0.34600 & 0.30140 & 0.24810 & 0.28200 & 0.29230 & 0.24810 & 0.28200 & 0.29230 \\
Alternative (A2) & 0.35940 & 0.34600 & 0.30700 & 0.31230 & 0.31340 & 0.30700 & 0.31230 & 0.31340 \\
Alternative (A3) & 0.24300 & 0.35940 & 0.33200 & 0.31530 & 0.30800 & 0.33200 & 0.31530 & 0.30800 \\
Alternative (A4) & 0.30140 & 0.24300 & 0.20240 & 0.21360 & 0.21820 & 0.20240 & 0.21360 & 0.21820 \\
Alternative (A5) & 0.34600 & 0.30700 & 0.31230 & 0.31340 & 0.30700 & 0.31230 & 0.31340 & 0.31450 \\
Alternative (A6) & 0.35940 & 0.33200 & 0.31530 & 0.30800 & 0.33200 & 0.31530 & 0.30800 & 0.31610 \\
Alternative (A7) & 0.24300 & 0.20240 & 0.21360 & 0.21820 & 0.20240 & 0.21360 & 0.21820 & 0.21460 \\
\hline
\end{tabular}




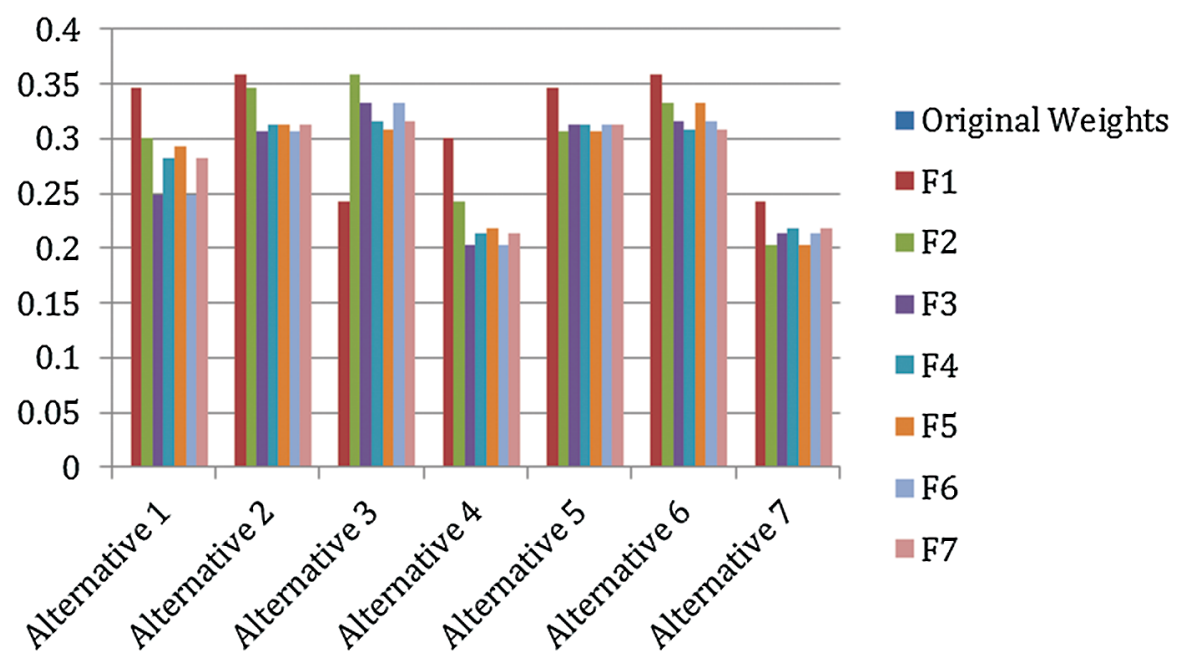

Figure 7: Graph of sensitivity analysis

\subsection{Comparison of Results}

Comparative study is an important aspect for validating the efficacy of the procedure/s used by the researchers. In order to perform a comparative study of the findings, we used another similar procedure known as classical ANP-TOPSIS. For assessment, it illustrates the representation of the findings gathered from various substitute procedures on the radar chart. The findings of the analysis are described in the Tab. 11 below along with all the findings of other procedures [22]. It shows that over the standard procedure, the fuzzy-based procedure is compatible with the study's results. The Tab. 11 and Fig. 8 shows a comparison of fuzzy ANP-TOPSIS with the Classical ANP-TOPSIS procedure.

Table 11: Comparisons between results

\begin{tabular}{lll}
\hline Alternatives & Fuzzy ANP-TOPSIS & Classical ANP-TOPSIS \\
\hline Alternative (A1) & 0.31215 & 0.29645 \\
Alternative (A2) & 0.32425 & 0.30475 \\
Alternative (A3) & 0.21245 & 0.19745 \\
Alternative (A4) & 0.27859 & 0.27859 \\
Alternative (A5) & 0.27854 & 0.25265 \\
Alternative (A6) & 0.28457 & 0.28458 \\
Alternative (A7) & 0.25658 & 0.26548 \\
\hline
\end{tabular}

\section{Discussion}

The social system does not respond to the epidemic with quality of service, as per the findings of this study. In particular, according to the experts, ambiguity is not acceptable for the social system in the midst of the epidemic possibility and it is important to adhere to the warnings regarding hand-washing and cleanliness, social isolation and staying home. Participants have noticed that Saudi Arabia's research society has an amazing skill to obey the law, perhaps. In addition, stakeholders have confidence in the government, the healthcare framework and medical facilities, and the continuity of the decisions of the nation in combating this health exigency. However, individuals must pay attention to the information 
disseminated by the media platforms and also to the accurate implementation of strategies. The findings show that the most influenced societal factor of Saudi Arabia is Finance or the financial constraints that the people are now beset with due to COVID-19 pandemic. The other social factors have been affected in the following descending order: Education, Relationship, Religion, Work, Psychological and Emotional.

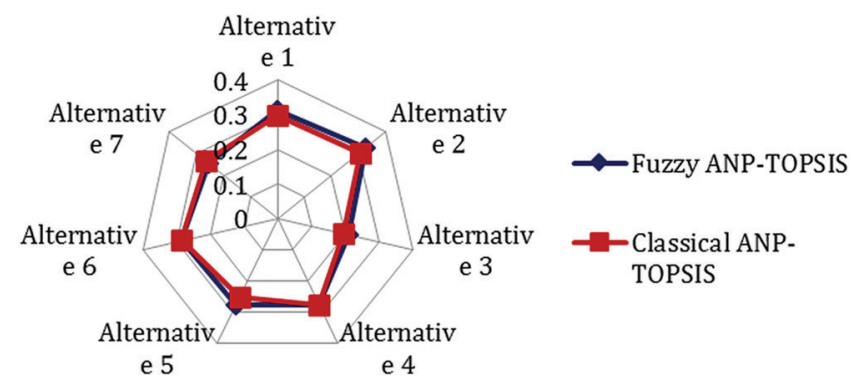

Figure 8: Radar chart representation of obtained comparative outcome

Ultimately, issues remain about financial measures that have been taken. General responses to the battle against pandemics by decision makers, teachers, public and especially the youth seem to be more constructive. Findings demonstrate that anyone with lower educational levels and earnings have higher levels of social trust. The combat against the epidemic novel coronavirus has been prolonged and is likely to impact various spectrums of the research society of Saudi Arabia. In addition, some of the effects may be far ranging, considering the extent of destruction and unleashed that this epidemic has unleashed, and could be tabulated at a much later date. Individuals need dedication and courage in such an uncertain scenario to maintain positive contact and also to meet their basic needs without any issues. In the early stages, our research was carried. It is really vital for individuals who are stuck in various locations due to quarantine to remain persistent in the prevalent social structure. Societal values may keep changing as long as the coronavirus debacle subsists. Therefore with the goal of safeguarding and even increasing community confidence, the government officials should reinforce their consistent and insightful perceptions. The media, in particular, should spread awareness in alignment with the sensibilities of the hapless citizens and ensure that information doesn't add to the mental despair. Perhaps most relevantly, information should be provided to be taken to enhance the confidence relating to economic measures.

\section{Conclusion}

Nations have already begun their fight against the COVID-19 outbreak which broke out in China and then spread to the other parts of the world. Any more harm likely to be caused by COVID-19 pandemic can be minimized by continuous mitigation procedures that can only be effective with social involvement. Hence for inspiring a more collective effort by the people, it is crucial to examine the affect of COVID-19 pandemic on various aspects of human life. Our initiative will assist the decision makers to enlist effective social strategies and implement the most viable measures to benefit the people. In the wake of massive financial setbacks for many, the governments of most of the countries have already announced a slew of economic measures along with an economic stimulus to boost the flailing economies. However, as shown by our analysis, financial concerns are the biggest apprehensions of people. This implies that the benefits of economic bailouts have yet not percolated to the common man. The present crisis mandates the restructuring of financial policies by the policy mappers. Comparable research work must be carried out at all periods with the intention of tracking changes, and therefore should be submitted without interruption to assist officials in updating their proposals and study. 
Acknowledgement: The authors acknowledges the Deanship of Scientific Research at King Faisal University for the financial support under Nasher Track (Grant no. 206064).

Funding Statement: Funding for this study was received from the Deanship of Scientific Research at King Faisal University, Kingdom of Saudi Arabia under Grant No. 206064.

Conflicts of Interest: The authors declare that they have no conflicts of interest to report regarding the present study.

\section{References}

[1] Science Daily, “COVID-19 Coronavirus Epidemic has a Natural Origin,” 2020. [Online]. Available: https://www. sciencedaily.com/releases/2020/03/200317175442.htm.

[2] World Health Organization, "COVID-19 public health emergency of international concern (PHEIC) global research and innovation forum," 2020. [Online]. Available: https://www.who.int/publications/m/item/covid-19public-health-emergency-of-international-concern-(pheic)-global-research-and-innovation-forum.

[3] WorldOMeters, "Coronavirus Cases," 2020. [Online]. Available: https:/www.worldometers.info/coronavirus/.

[4] Download the Daily Number of New Reported Cases of COVID-19 by Country Worldwide, "European Centre for Disease Prevention and Control: An Agency of the European Union," 2020. [Online]. Available: https://www. ecdc.europa.eu/en/publications-data/download-todays-data-geographic-distribution-covid-19-cases-worldwide.

[5] A. Attaallah, M. Ahmad, A. H. Seh, A. Agrawal, R. Kumar et al., "Estimating the impact of COVID-19 pandemic on the research community in the kingdom of Saudi Arabia," CMES-Computer Modeling in Engineering \& Sciences, vol. 126, no. 1, pp. 419-436, 2021.

[6] K. Sahu and Rajshree, "Stability: abstract roadmap of security," American International Journal of Research in Science, Engineering \& Mathematics, vol. 2, no. 9, pp. 183-186, 2015.

[7] S. A. Khan, M. Alenezi, A. Agrawal, R. Kumar and R. A. Khan, "Evaluating performance of software durability through an integrated fuzzy-based symmetrical method of ANP and TOPSIS," Symmetry, vol. 12, no. 4, pp. 1-15, 2020.

[8] R. Kumar, S. A. Khan and R. A. Khan, "Durability challenges in software engineering," Crosstalk, vol. 29, no. 5, pp. 29-31, 2016.

[9] A. Agrawal, M. Zaroor, M. Alenezi, R. Kumar and R. A. Khan, "Security durability assessment through fuzzy analytic hierarchy process," PeerJ Computer Science, pp. 1-43, 2019.

[10] K. Sahu and R. K. Srivastava, "Soft computing approach for prediction of software reliability," ICIC Express Letters, vol. 12, no. 12, pp. 1213-1222, 2018.

[11] R. Kumar, A. I. Khan, Y. B. Abushark, M. M. Alam, A. Agrawal et al., "An integrated approach of fuzzy logic, AHP and TOPSIS for estimating usable-security of web applications," IEEE Access, vol. 8, no. 8, pp. 5094450957, 2020.

[12] T. L. Saaty, Decision Making with Dependence and Feedback: The Analytic Network Process. New York Public Library, USA: RWS Publications, 1996. [Online]. Available: https://books.google.co.in/books/about/Decision_ Making_with_Dependence_and_Feed.html?id=MGpaAAAAYAAJ.

[13] K. Sahu and R. K. Srivastava, "Needs and importance of reliability prediction: an industrial perspective," Information Sciences Letters, vol. 9, no. 1, pp. 33-37, 2020.

[14] A. Agrawal, M. Alenezi, R. Kumar and R. A. Khan, "Measuring the sustainable-security of web applications through a fuzzy-based integrated approach of AHP and TOPSIS," IEEE Access, vol. 7, no. 7, pp. 153936153951, 2019.

[15] K. Sahu and R. K. Srivastava, "Revisiting software reliability," Advances in Intelligent Systems and Computing, vol. 802, pp. 221-235, 2019.

[16] C. L. Hwang and K. Yoon, "Methods for multiple attribute decision making," Lecture Notes in Economics and Mathematical Systems, Springer, vol. 186, no. 5, pp. 58-191, 1981. 
[17] C. T. Chen, "Extensions of the TOPSIS for group decision-making under fuzzy environment," Fuzzy Sets and Systems, vol. 114, no. 1, pp. 1-9, 2000.

[18] M. T. J. Ansari, D. Pandey and M. Alenezi, "STORE: Security threat oriented requirements engineering methodology," Journal of King Saud University-Computer and Information Sciences, pp. 1-18, Article in Press, 2018.

[19] K. Sahu, R. Shree and R. Kumar, "Risk management perspective in SDLC," International Journal of Advanced Research in Computer Science and Software Engineering, vol. 4, no. 3, pp. 1247-1251, 2014.

[20] M. Zarour, M. T. J. Ansari, M. Alenezi, A. K. Sarkar, M. Faizan et al., "Evaluating the impact of blockchain models for secure and trustworthy electronic healthcare records," IEEE Access, vol. 8, no. 8, pp. 157959157973, 2020.

[21] K. Sahu, F. A. Alzahrani, R. K. Srivastava and R. Kumar, "Hesitant fuzzy sets based symmetrical model of decision-making for estimating the durability of web application," Symmetry, vol. 12, no. 6, pp. 1770-1792, 2020.

[22] R. Kumar, M. Alenezi, M. T. J. Ansari, B. Gupta, A. Agrawal et al., "Evaluating the impact of malware analysis techniques for securing web applications through a decision-making framework under fuzzy environment," International Journal of Intelligent Engineering and Systems, vol. 13, no. 6, pp. 94-109, 2020.

[23] A. Agrawal, M. Alenezi, S. A. Khan, R. Kumar and R. A. Khan, "Multi-level fuzzy system for usable-security assessment," Journal of King Saud University-Computer and Information Sciences, Elsevier, pp. 1-9, 2019.

[24] A. Algarni, M. Ahmad, A. Attaallah, A. Agrawal, R. Kumar et al., "A hybrid fuzzy rule-based multi-criteria framework for security assessment of medical device software," International Journal of Intelligent Engineering \& Systems, vol. 13, no. 6, pp. 51-62, 2020.

[25] R. Kumar, S. A. Khan, A. Agrawal and R. A. Khan, "Security assessment through fuzzy Delphi analytic hierarchy process," ICIC Express Letters, vol. 12, no. 10, pp. 1053-1060, 2018.

[26] C. W. Chang, C. R. Wu and H. L. Lin, "Integrating fuzzy theory and hierarchy concepts to evaluate software quality," Software Quality Journal, vol. 16, no. 2, pp. 263-276, 2008. 